\title{
A Scheme for Evaluating Feral Horse Management Strategies
}

\author{
L. L. Eberhardt and J. M. Breiwick \\ National Marine Fisheries Service, National Marine Mammal Laboratory, 7600 Sand Point Way, \\ NE, Bldg. 4, Seattle, WA 98115, USA
}

Correspondence should be addressed to L. L. Eberhardt, leberhardt@aol.com

Received 26 December 2011; Revised 26 March 2012; Accepted 27 March 2012

Academic Editor: Bradford Hawkins

Copyright (c) 2012 L. L. Eberhardt and J. M. Breiwick. This is an open access article distributed under the Creative Commons Attribution License, which permits unrestricted use, distribution, and reproduction in any medium, provided the original work is properly cited.

\begin{abstract}
Context. Feral horses are an increasing problem in many countries and are popular with the public, making management difficult. Aims. To develop a scheme useful in planning management strategies. Methods. A model is developed and applied to four different feral horse herds, three of which have been quite accurately counted over the years. Key Results. The selected model has been tested on a variety of data sets, with emphasis on the four sets of feral horse data. An alternative, nonparametric model is used to check the selected parametric approach. Conclusions. A density-dependent response was observed in all 4 herds, even though only 8 observations were available in each case. Consistency in the model fits suggests that small starting herds can be used to test various management techniques. Implications. Management methods can be tested on actual, confined populations.
\end{abstract}

\section{Introduction}

Feral horses continue to be a problem in the Western United States $[1,2]$ and elsewhere [3]. Some recent studies provide the basis for a simple model that should be useful in developing management approaches, and these are assessed here, along with the basis for selecting a model.

We have located 4 data sets on feral horses that may serve as a basis for designing tests of management schemes. These data come from widely dispersed locations (Argentina, France, and the United States). The studies were conducted on horse herds confined to fenced areas. Two of the studies were conducted in relatively small areas, making replication quite feasible. The other two were based on sizable populations and would thus be expensive to replicate.

The Argentine study was conducted on an isolated (but sizable) herd that was enumerated very carefully. All 4 studies gave clear evidence of density dependence in a relatively short period ( 8 years). Our proposal is to emulate these studies (in fenced areas) to test various management schemes, such as reproductive inhibition and the removal of the young females that are readily adopted. A successful approach would be evidenced by a substantial reduction in population growth. Presumably control measures would be applied while the population is well below the inflection point in the growth curve and that the test populations could then be maintained long enough to ascertain the efforts required for continued control.

\section{Material and Methods}

2.1. Population Growth Curves. Perhaps the most popular model for population growth is the generalized logistic of Nelder [14], Pella and Tomlinson [15], best-known from Ayala et al. [16], and often termed the theta logistic. The model is

$$
N(t)=\left[K^{-z}-\left(K^{-z}-N_{0}^{-z}\right) e^{-r z t}\right]^{-1 / z} .
$$

The corresponding difference equation is

$$
N(t)=N(t-1)+r N(t-1)\left[1-\left(\frac{N(t-1)}{K}\right)^{z}\right] .
$$

Recently, this model has been shown to have some shortcomings $[17,18]$, so we here use a simplification in which the parameter controlling the inflection point $(z)$ is set to 2.0:

$$
N(t)=\left[K^{-2}-\left(K^{-2}-N_{0}^{-2}\right) e^{-r 2 t}\right]^{-1 / 2} .
$$


TABLE 1: Estimates of the parameter $z$ in (1).

\begin{tabular}{|c|c|c|c|}
\hline Species & $z$ & $\begin{array}{l}\text { Standard } \\
\text { error }\end{array}$ & $\begin{array}{l}\text { Coef. of } \\
\text { Variation }\end{array}$ \\
\hline Red deer 6585 & 3.89 & 1.06 & 0.272 \\
\hline Boar 9428 & 4.99 & 5.68 & 1.138 \\
\hline Gray fox 319 & 3.78 & 1.54 & 0.407 \\
\hline Gray fox 342 & 1.85 & 2.13 & 1.151 \\
\hline Coyote 263 & 1.93 & 2.86 & 1.482 \\
\hline $\begin{array}{l}\text { Gray seals Bonner (1975) } \\
{[4]}\end{array}$ & 11.76 & 10.37 & 0.882 \\
\hline Bison Fredin (1984) [5] & 0.75 & 0.47 & 0.627 \\
\hline Macaque 6068 & 16.26 & 25.12 & 1.545 \\
\hline Beaver 151 & 0.46 & 0.8 & 1.739 \\
\hline Beaver 156 & 7.43 & 7.63 & 1.027 \\
\hline $\begin{array}{l}\text { Elephant seals Stewart } \\
\text { et al. (1994) [6] }\end{array}$ & 1.86 & 0.67 & 0.36 \\
\hline $\begin{array}{l}\text { Seneca deer Hesselton } \\
\text { et al. (1965) [7] }\end{array}$ & 0.69 & 0.45 & 0.652 \\
\hline Badger 78 & 1.76 & 4.08 & 2.29 \\
\hline $\begin{array}{l}\text { Fur seals Kenyon et al. } \\
(1954)[8]\end{array}$ & 4.05 & 3.17 & 0.783 \\
\hline $\begin{array}{l}\text { Blue Springs manatees } \\
\text { Eberhardt and O'Shea } \\
\text { (1995) [9] }\end{array}$ & 5.08 & 10.71 & 2.108 \\
\hline $\begin{array}{l}\text { Chinstrap penguins } \\
\text { Fraser (pers. commun.) }\end{array}$ & 0.45 & 2.6 & 5.778 \\
\hline $\begin{array}{l}\text { Gentoo penguins Fraser } \\
\text { (pers. commun.) }\end{array}$ & 0.69 & 1.44 & 2.087 \\
\hline Polar bear 143 & 6.13 & 6.91 & 1.127 \\
\hline Beaver 156 & 7.43 & 7.63 & 1.02 \\
\hline Coyote 247 & 6.42 & 10.74 & 1.673 \\
\hline Gray fox 328 & 1.88 & 2.43 & 1.293 \\
\hline Boar 9429 & 1.66 & 0.99 & 0.596 \\
\hline Marten 9695 & 1.2 & 2.27 & 1.892 \\
\hline Squirrel 9699 & 0.98 & 2.05 & 2.92 \\
\hline Gray fox 334 & 0.45 & 3.48 & 2.48 \\
\hline Median & 1.88 & & \\
\hline
\end{tabular}

The basis for this result appears in Eberhardt and Breiwick [19]. The corresponding difference equation is (2) with $z=$ 2. An alternative, nonparametric model is

$$
y=b_{0}+b_{1} t_{1}+b_{2} t^{2} .
$$

It can readily be fit as a linear model and used to derive confidence limits, following Draper and Smith [20].

If we set $z=1 \mathrm{in}$ (1), the well-known ordinary logistic curve results, tracing back to Verhulst in 1844:

$$
N(t)=\frac{K}{1+c e^{-r t}}, \quad c=\frac{K}{N_{0}}-1 .
$$

The proportion of the asymptotic population size present at the inflection point can be defined as [21]:

$$
p=\left(\frac{1}{1+z}\right)^{1 / z} \text {. }
$$

With $z=2$, this is $p=0.58$. This result is to be expected in that it has been known for some time that the inflection point in population growth curves often is higher than the $50 \%$ level of the ordinary logistic curve $[22-25]$. $K$ denotes the asymptotic value, and $r$ is the rate of increase, $z$ governs the inflection point of the curve, and $N$ denotes population size. The curves were fit with nonlinear least-squares [26], as implemented in the R-language [27].

Part of the data used here (Table 1) was obtained from the Global Population Dynamics Database (GPDD) maintained by the National Environmental Research Council at http://www.sw.ic.ac.uk/cpb/cpb/gpdd.html). Sources for some additional sets and the corresponding references are listed in Table 1.

2.2. Biases in Estimation. There is a large recent literature concerned with various error terms in population models ([18, 28-30] provide examples). Much of the literature on biases is concerned with decreasing populations, rather than with the growth curves considered here, and it seems that there is little agreement yet on terms and methodology. We believe that the dominant sources are "observation error" resulting from inaccuracies in counting and "process error" which may result from various sources, such as fluctuations due to changing age structure as populations increase. Because our major proposal is concerned with devising methods to stop population growth, biases of the kind described above are largely neglected here. We have examined growth curves for some populations that have been counted very accurately, usually by corralling the populations, so that "observational error" is absent or negligible, and the fluctuations present are largely due to "process error." Very likely, the two sources are independent ("observational error" can scarcely be influenced by "process error" unless the latter is very large indeed). Hence, we believe that it is reasonable to assume that the two sources are additive and might be treated, at least approximately, by assuming a single-error term in curve fitting. We thus assume that the calculations underlying Table 1 provide useful estimates of the parameter $z$, governing the inflection point.

\section{Results}

Figure 1 shows fits of the modified logistic curve (3) to the four wild horse data sets in the left-hand column. Confidence limits (95\%) for (4) are shown by crosses. The right-hand column contains the corresponding fits from the "Sibly equation" [31-34] resulting from a rearrangement of (2), again with $z=2$ :

$$
p g r=\frac{N(t)}{N(t-1)}-1=r\left[1-\left(\frac{N(t-1)}{K}\right)^{2}\right] .
$$

Table 1 provides data on estimates of the parameter $z$ in (1) from 25 data sets and shows that the median value is close to the value (2) used in (3).

Table 2 gives the parameters from fitting (3) to the four data sets on wild horses. All four have fairly large values 

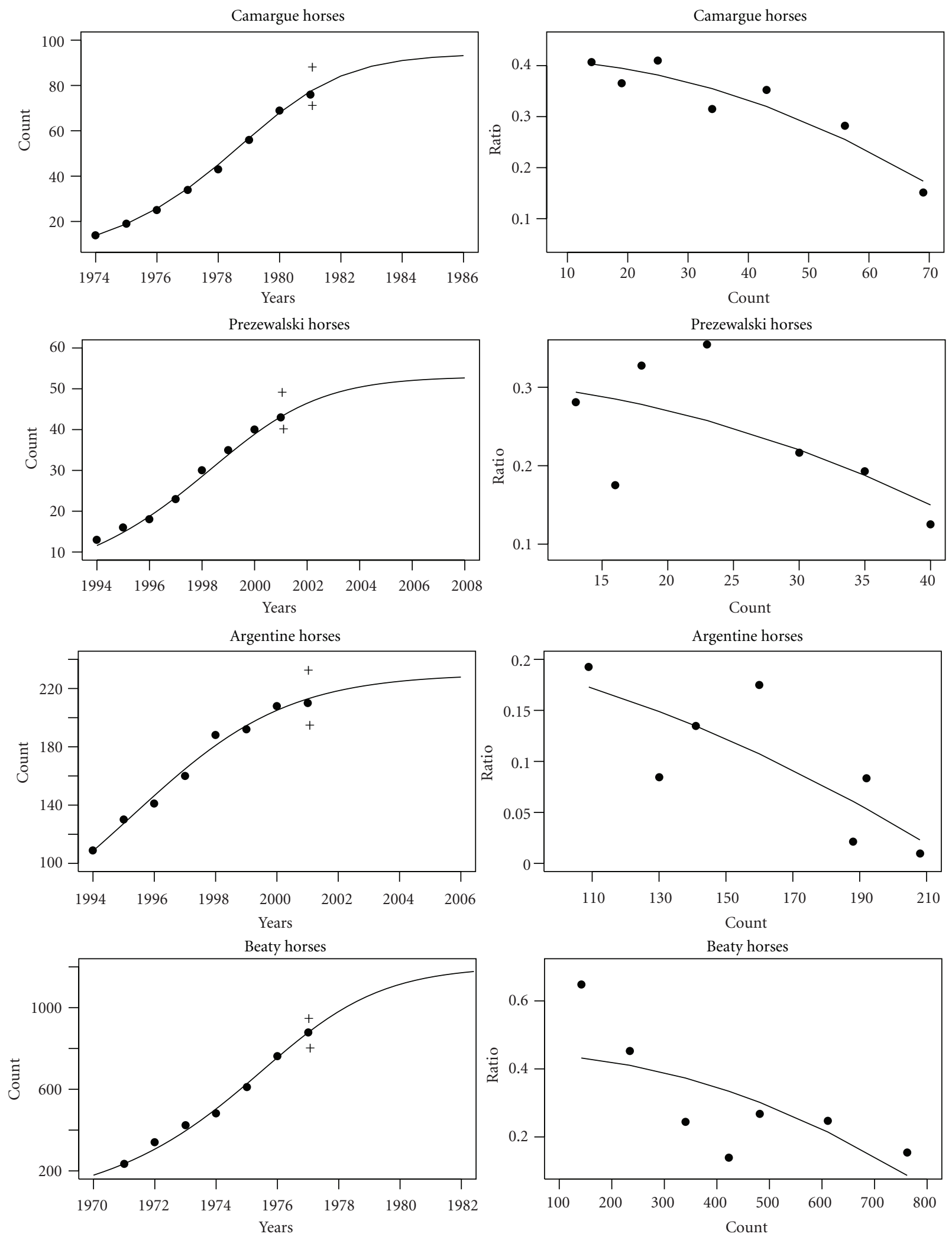

FIGURE 1: Left-hand panel: fits of the modified logistic curve (3) with 95\% confidence limits derived from (4); right-hand panel: fits of the Sibly model (7) to the same data. 
TABLE 2: Data on horse herds.

\begin{tabular}{|c|c|c|c|c|c|c|}
\hline Herd & $\begin{array}{l}\text { Scientific } \\
\text { name }\end{array}$ & K & $r$ & $N_{0}$ & $\begin{array}{c}\text { Standard } \\
\text { error of } \\
K\end{array}$ & Source \\
\hline Camargue & $\begin{array}{l}\text { Equis } \\
\text { cabella }\end{array}$ & 94 & 0.326 & 10 & 1.08 & $\begin{array}{c}\text { Grange et al. } \\
2009[10]\end{array}$ \\
\hline Prezewalski & $\begin{array}{l}\text { Equis } \\
\text { ferus }\end{array}$ & 53 & 0.262 & 9 & 1.08 & $\begin{array}{c}\text { Tatin et al. } 2009 \\
{[11]}\end{array}$ \\
\hline Argentine & $\begin{array}{l}\text { Equis } \\
\text { cabella }\end{array}$ & 230 & 0.216 & 91 & 5.12 & $\begin{array}{c}\text { Scorolli and } \\
\text { Lopez-Cazarola } \\
2010[12]\end{array}$ \\
\hline Beaty & $\begin{array}{l}\text { Equis } \\
\text { cabella }\end{array}$ & 1202 & 0.28 & 136 & 28.23 & $\begin{array}{l}\text { Eberhardt et al. } \\
\quad 1982[13]\end{array}$ \\
\hline
\end{tabular}

of $r$, compared to many other birds and mammals, and relatively small standard errors, as might be expected due to the accurate counts. Two populations (Argentine and Beaty horses) started out with sizable initial populations. All four populations grew beyond the inflection point within 8 years. We fitted the generalized logistic curve (1), the logistic curve (5), and the Sibly curve (7) to the data and checked to see if the fitted curves passed through the confidence limits shown in Figure 1. The Beaty horse data were too variable for satisfactory convergence, and the Sibly model yielded values above the upper confidence limit for the Camargue (87) and Prezewalski (52) herd data. The remaining curves fell within the confidence interval.

\section{Discussion}

As indicated in the Introduction above, our purpose is to identify a simple model for the growth of wild horse populations that should be useful in evaluating management strategies. In spite of the small sample sizes (8 observations in each case), it appears that the curves provide useful fits to the data with moderate coefficients of variation for estimates of the asymptotic values ( $4 \%$ for the Camargue horses, $8 \%$ for the Prezewalski horses, 5\% for the Argentine horses, and 17\% for the Beaty horse example). The high CV for Beaty horses likely is a consequence of the fact that the maximal count fell some distance below the estimated asymptote. Rates of increase (Table 2) were in reasonable agreement with a value obtained from reproductive and survival data on feral horses [35]. It should be noted, however, that the rate of increase given by Eberhardt [35] is based on assuming an exponential model, which is not as suitable for feral horses as is (3) which accommodates the decline in growth rate as the population increases.

\section{Management Implications}

We have identified 4 cases (on 4 quite different locations) where feral horse data is usefully described by a simple model, the modified logistic curve of (3). All of the populations were either in areas remote from other feral horse populations (Argentine) or enclosed in fences and provided useful estimates of the asymptotic value and of the rates of increase. Actual applications for management purposes will depend on circumstances and the management method to be tested. We believe that tests should be conducted in fenced areas, with a known initial population. Very likely, the initial populations should be below those observed for the Argentine and Beaty herds. As noted in the Introduction, if control is achieved, the resulting population should be maintained for some time to determine how long a given method will maintain control and what efforts are required to maintain control. Costs of fencing and maintaining a site may be significant, and it may be possible to do some tests in areas isolated from other herds.

\section{Acknowledgments}

The authors acknowledge support from the National Marine Fisheries Agency and the US Marine Mammal Commission.

\section{References}

[1] B. Abbey, "Managing wild horses on public lands," Wildlife Professional:10, 2010.

[2] J. Jeffries and P. Rouch, "Lethal hoofbeats," Wildlife Professional: 50-55, 2010.

[3] M. Thomas, "Is shooting the answer downunder?" Wildlife Professional 57, 2010.

[4] W. N. Bonner, "Population increase of grey seals at the Farne Islands. Biology of the seal," in Rapports et Proces-Verbaux des Reunions, K. Ronald and A. W. Mansfield, Eds., vol. 169, pp. 366-370, Conseil International pour l'Exploration de la Mer, 1975.

[5] R. A. Fredin, "Levels of maximum net productivity in populations of large terrestrial mammals. Reproduction in whales, dolphins, and porpoises," in Reports of the International Whaling Commission, W. F. Perrin, R. L. Brownell, and D. P. DeMaster, Eds., no. 6, pp. 381-387, International Whaling Commission, Cambridge, UK, 1984.

[6] B. S. Stewart, P. K. Yoachem, H. R. Huber et al., "History and present status of the northern elephant seal population," in Elephant Seals, Population Ecology, Behavior, and Physiology, B. J. LeBouef and R. M. Laws, Eds., pp. 29-48, University of California Press, Berkeley, Calif, USA, 1994.

[7] W. T. Hesselton, C. W. Sevringhaus, and J. E. Tanck, "Population dynamics of deer in the Seneca army depot," New York Fish and Game Journal, vol. 12, pp. 17-30, 1965.

[8] K. W. Kenyon, V. H. Scheffer, and D. G. Chapman, "A Population Study of the Alaska Fur Seal Herd," Special Scientific Report, Wildlife No. 12, United States Department of the Interior, U. S. Fish and Wildlife Service, Washington, DC, USA, 1954.

[9] L. L. Eberhardt and T. J. O'Shea, "Integrating manatee life history data and population model development," in Population Biology of the Florida Manatee, T. J. O'Shea, B. B. Ackerman, and H. F. Percival, Eds., National Biological Service Technical Report Series, pp. 269-278, Information and Technology Report 1, Fort Collins, Colo, USA, 1995.

[10] S. Grange, P. Duncan, and J. M. Gaillard, "Poor horse traders: large mammals trade survival for reproduction during the process of feralization," Proceedings of the Royal Society B, vol. 276, no. 1663, pp. 1911-1919, 2009.

[11] L. Tatin, S. R. B. King, B. Munkhtuya, A. J. M. Hewison, and C. Feh, "Demography of a socially natural herd of Przewalski's 
horses: an example of a small, closed population," Journal of Zoology, vol. 277, no. 2, pp. 134-140, 2009.

[12] Scorolli and A. L. A. C. Lopez-Cazarola, "Demography of feral horses (Equus caballus): a long-term study in Tompquist Park, Argentina," Wildlife Research, vol. 37, no. 3, pp. 207-214, 2010.

[13] L. L. Eberhardt, A. K. Majorowicz, and J. A. Wilcox, "Apparent rates of increase for two feral horse herds," The Journal of Wildlife Management, vol. 46, pp. 367-374, 1982.

[14] J. A. Nelder, "The fitting of a generalization of the logistic curve," Biometrics, vol. 17, pp. 89-110, 1961.

[15] J. J. Pella and P. K. Tomlinson, "A generalized stock production model," Bulletin of the Inter-American Tropical Tuna Commission, vol. 13, pp. 419-496, 1969.

[16] F. J. Ayala, M. E. Gilpin, and J. G. Ehrenfeld, "Competition between species: theoretical models and experimental tests," Theoretical Population Biology, vol. 4, no. 3, pp. 331-356, 1973.

[17] L. Polansky, P. de Valpine, J. O. Lloyd-Smith, and W. M. Getz, "Likelihood ridges and multimodality in population growth rate models," Ecology, vol. 90, no. 8, pp. 2313-2320, 2009.

[18] F. Clark, B. W. Brook, S. Delean, H. R. Akcakaya, and C. J. A. Bradshaw, "The theta-logistic is unreliable for modeling most census data," Methods in Ecology and Evolution, vol. 1, pp. 253262,2010 .

[19] L. L. Eberhardt and J. M. Breiwick, "2012. Models for population growth curves," ISRN Ecology, vol. 2012, Article ID 815016, 7 pages, 2012.

[20] N. R. Draper and H. Smith, Applied Regression Analysis, Wiley, 3rd edition, 1998.

[21] L. L. Eberhardt, "Population projections from simple models," Journal of Applied Ecology, vol. 24, no. 1, pp. 103-118, 1987.

[22] D. S. Butterworth and P. B. Best, "The origins and choice of $54 \%$ carrying capacity as the protection level for baleen whale stocks, and the implications thereof for management procedures," Reports International Whaling Commission, vol. 44, pp. 491-497, 1994.

[23] L. L. Eberhardt, "Optimal policies for conservation of large mammals, with special reference to marine ecosystems," Environmental Conservation, vol. 4, no. 3, pp. 205-212, 1977.

[24] L. L. Eberhardt and D. B. Siniff, "Population dynamics and marine mammal management policies," Journal of the Fisheries Research Board of Canada, vol. 34, pp. 183-190, 1977.

[25] C. W. Fowler, "Density dependence as related to life history strategy," Ecology, vol. 62, pp. 602-610, 1981.

[26] D. M. Bates and D. G. Watts, Nonlinear Regression Analysis and Its Applications, John Wiley \& Sons, New York, NY, USA, 1988.

[27] R Development Core Team, "R: a language and environment for statistical computing," R Foundation for Statistical Computing, Vienna, Austria, 2004, http://www.R-project.org/.

[28] J. P. Buonaccorsi and J. Staudenmayer, "Statistical methods to correct for observation error in a density-independent population model," Ecological Monographs, vol. 79, no. 2, pp. 299-324, 2009.

[29] E. E. Holmes, J. L. Sabo, S. V. Viscido, and W. F. Fagan, "A statistical approach to quasi-extinction forecasting," Ecology Letters, vol. 10, no. 12, pp. 1182-1198, 2007.

[30] D. F. Staples, M. L. Taper, and B. Dennis, "Estimating population trend and process variation for PVA in the presence of sampling error," Ecology, vol. 85, no. 4, pp. 923-929, 2004.

[31] R. M. Sibly, D. Barker, M. C. Denham, J. Hone, and M. Pagel, "Ecology: on the regulation of populations of mammals, birds, fish, and insects," Science, vol. 309, no. 5734, pp. 607-610, 2005.
[32] B. W. Brook and C. J. A. Bradshaw, "Strength of evidence for density dependence in abundance time series of 1198 species," Ecology, vol. 87, no. 6, pp. 1445-1451, 2006.

[33] B. E. Sæther, V. Grotan, P. Tryjanowski, C. Barbraud, S. Engen, and M. Fulin, "Climate and spatio-temporal variation in the population dynamics of a long distance migrant, the white stork," Journal of Animal Ecology, vol. 75, no. 1, pp. 80-90, 2006.

[34] A. Berryman and M. Lima, "Detecting the order of population dynamics from time series: nonlinearity causes spurious diagnosis," Ecology, vol. 88, no. 8, pp. 2121-2123, 2007.

[35] L. L. Eberhardt, "A paradigm for population analysis of longlived vertebrates," Ecology, vol. 83, no. 10, pp. 2841-2854, 2002. 

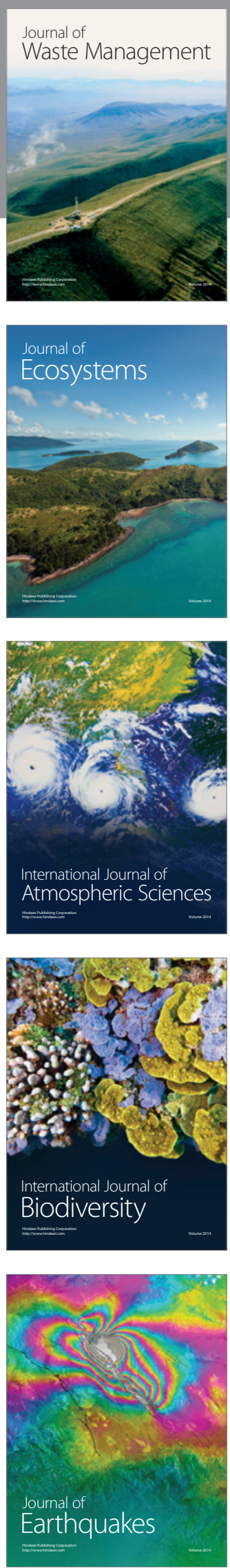
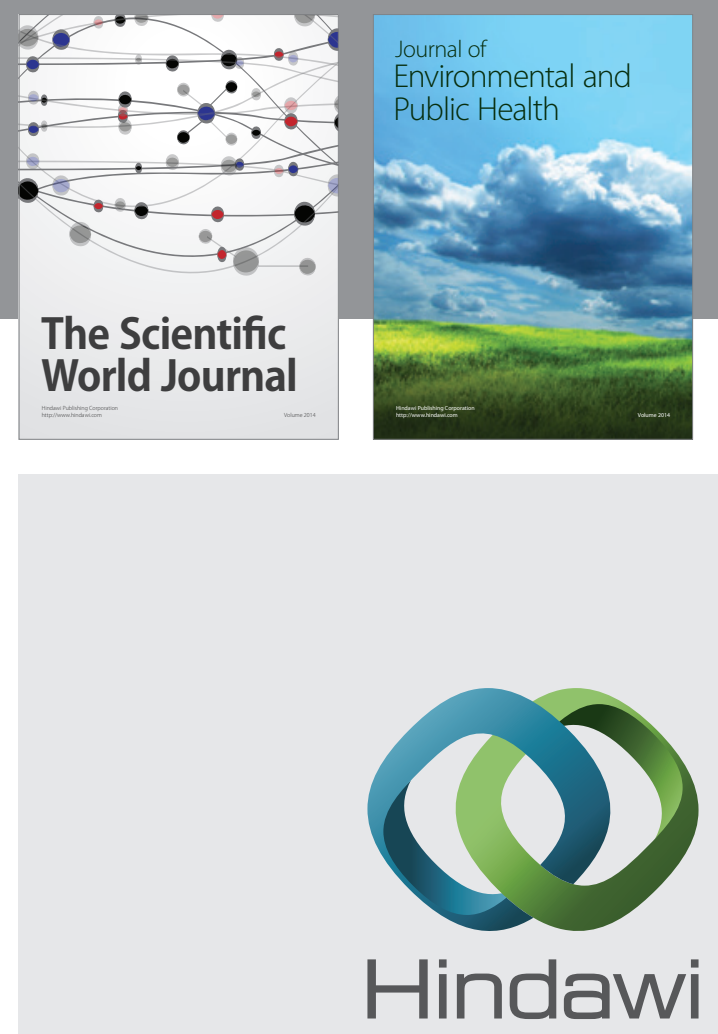

Submit your manuscripts at

http://www.hindawi.com
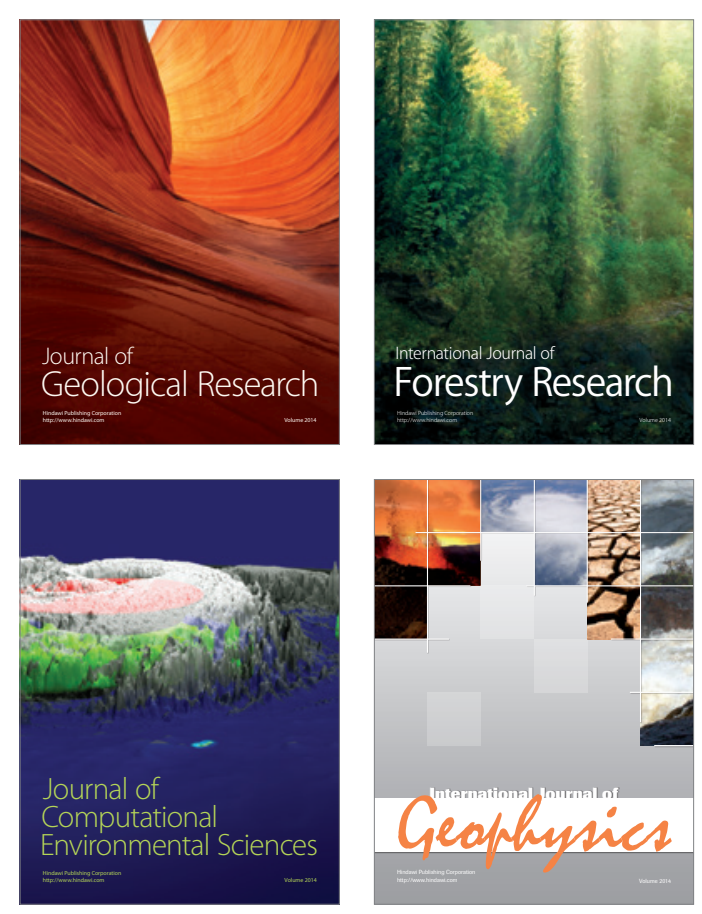
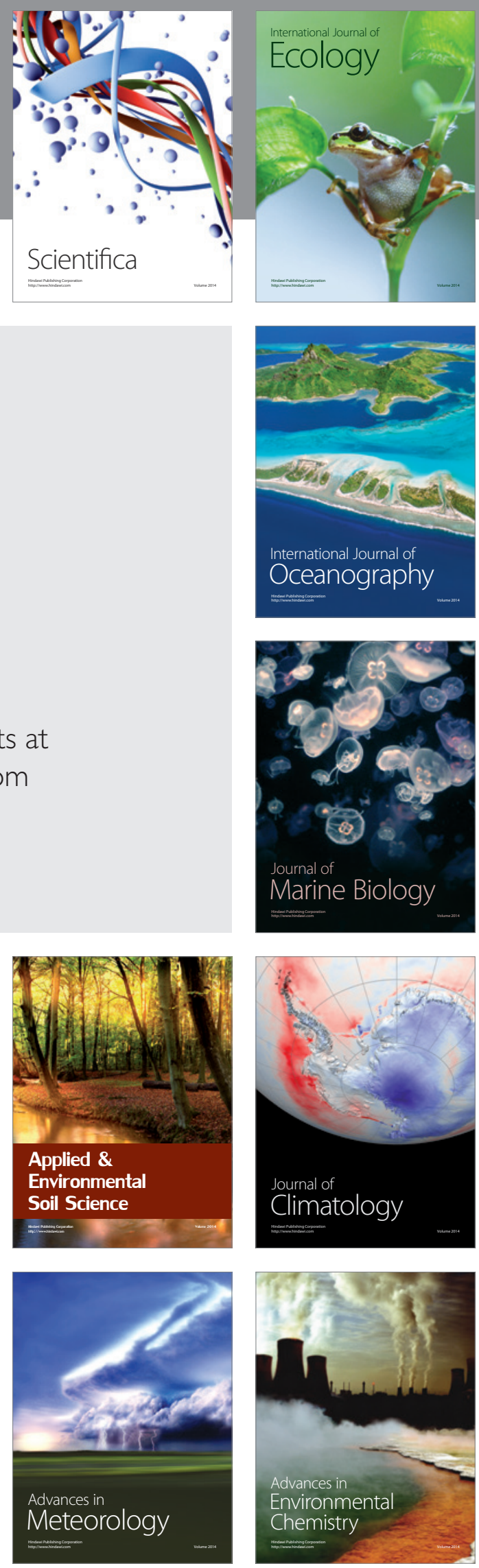